\title{
Bioremediation- A Beneficial Use of Biotechnology and Allied Engineering Technologies in Oil Producing Regions
}

\author{
Muhammad Mukhtar ${ }^{a} *$ and Larry D Griffin ${ }^{b}$ \\ ${ }^{a}$ Department of Biotechnology, American University of Ras Al Khaimah, UAE \\ ${ }^{b}$ Department of Languages and Literature, American University of Ras Al Khaimah, UAE
}

\begin{abstract}
Microbial decomposition has played a major role in the sustenance of societies by decomposing various materials thus enhancing physical space on the earth. However, a continuous increase in world population now threatens the carrying capacity of our planet. Within a defined space on Earth, the ever increasing number of living organisms creates challenges for the management of waste materials generated. Identification and isolation of microbes capable of decomposing wastes and hazardous materials and discovery of processes to produce genetically engineered microorganisms (GEMS) through biotechnological processes give hope to making this world a better place to live by managing global wastes using tamed microorganisms. Scientists coin this process of utilizing GEMS with defined characteristics of decontaminating waste and harmful materials as bioremediation. In this study, we evaluate relative scientific data from bioremediation and oil spills in the Middle East. The US National Library of Medicine, National Institutes of Health, PubMed and PubMed Health databases were used for retrieving information relevant to application of bioremediation in oil spills and issues associated with oil contamination in peripheries of oil drilling areas. The size of these databases gradually increase, however, based on our access in the last week of October 2015, the word "bioremediation" search on the PubMed databases returned above 36,000 articles, and among these a combined search of "bioremediation AND Oil" returned 2,400 articles which shows that 7\% of global research in the area of bioremediation is dedicated towards oil cleaning. A further refining of the search in reference to Middle East (bioremediation AND Oil AND Middle East) returns 41 articles thus revealing 1.7\% of the research activities occur in the Middle East. According to the US Energy Information Administration, the Middle East harbors 49\% reserves of crude oil, whereas, it shares a significantly weaker output as far as scientific contributions remain. Based on this information, we provide our analyses of the ongoing bioremediation in general with a particular focus on oil and propose strengthening of biotechnology programs in collaboration with the discipline of engineering to foster research in oil bioremediation in the Middle East
\end{abstract}

\section{Introduction}

Utilization of bacteria, fungi, and plants to remove or neutralize contaminants from soil and water is called bioremediation. Microbes have always played a major role in decomposing hazardous wastes; however, recent genetic manipulation technologies unleashed the immense potential of creating microorganism and plants with defined characteristics and capabilities.

${ }^{*}$ Corresponding author

E-mail: muhammad.mukhtar@aurak.ac.ae

(C) 2015 International Association for Sharing Knowledge and Sustainability

DOI: $10.5383 /$ swes.7.02.005
Over the last couple of decades by producing microbes with a probability of accomplishing a defined decontamination strategy sometime isolating them from natural environments, and augmenting their growth has emerged as an ever expanding industry with unlimited growth potentials. According to a report generated in the past decade by Frost and Sullivan Research Services on "US Bioremediation Markets" released in the year 2003': "The bioremediation applications 
yet to be explored are limitless and the Government's R\&D initiatives and funding decisions seem to favor continued pursuit of these technologies." The interest in bioremediation technologies and its allied fields like biotechnology and engineering increases day by day and a recent report entitled "Bioremediation Technologies and Services Market - Global Industry Analysis, Size, Share, Growth, Trends and Forecast, 2013 -2019" by the Transparency Market Research ${ }^{2}$ states: "The overall bioremediation technologies and services market is expected to witness an admirable growth due to the increasing awareness for environmental safety and protection. Moreover, stringent government regulations and policies for environmental restoration initiatives are further fuelling the popularity of biotechnology based bioremediation technologies and services globally."

Utilization of microorganisms for removing contaminants from water dates back to $600 \mathrm{BC}$; however, industrial potential of bioremediation, first recognized in the year 1989, results from its usage subsequent to Exxon Valdez oil spill in Alaska one of the largest spills in the history; the ship released 11 million gallons of oil and much of this washed onto the shoreline creating slick surfaces in an area exceeding 500 kilometers. Several strategies for cleaning shoreline met with disappointing consequences. However, fertilizer application previously shown to enhance growth of hydrocarbons (major constituents of oil) degrading bacteria miraculously led to major cleaning of shorelines. Fertilizers application, significantly augmenting bacterial population capable of degrading hydrocarbons, ultimately led to clean surfaces thus providing proof of the concept for industrial application of microorganisms.

Bioremediation technology utilizes isolation of microorganisms from natural environments, performing removal of harmful agents and optimizing their growth conditions in laboratory before releasing in field, or endowing bacteria and fungi with characteristics that remove nonbiodegradable pollutants through manipulating their genetic characteristics by biotechnology practices. Mycoremediation utilizes fungi and phytoremediation by plants based on the living organisms provide environmental friendly services. Several other terminologies like air-sparging (removing contaminants through volatilization), biostimulation (enhancing growth of biodegrading bacteria through adding specialized nutrients), bioaugmentation (adding actively growing microbes with biodegrading characteristics), bioventing (enhancing aerobic or anaerobic environment for biodegrading microorganisms), bioslurping (vacuum mediated bioventing) define the technology components of bioremediation.

We report here research gaps in oil producing countries in the area of bioremediation mainly in reference to the Middle East by analyzing available exclusive data in public domain database MEDLINE (Medical Literature Analysis and Retrieval System Online, or MEDLARS Online), a bibliographic database of life sciences and biomedical information. The PubMed search engine was used to retrieve desired information. Established and maintained by The United States National Library of Medicine (NLM) at the National Institutes of Health (NIH) as of October 2015, this database contains 25 million citations (records) for biomedical literature. Furthermore, our data proposes implementation of strong interdisciplinary program in the area of biotechnology and engineering to increase the focus on bioremediation strategies for oil and its various byproducts.

\section{Materials and Methods}

We used PubMed Simple Subject and Boolean searches to retrieve scientific literature relevant to bioremediation. PubMed is repository of biomedical literature from MEDLINE, life sciences journals and online books ${ }^{3}$. Our simple subject search using term bioremediation returned 36,017 scientific records (accessed on October 30, 2015). We used Boolean operator $A N D$ that defines a logical relationship between or among search terms to make searches for and identifying relation to "bioremediation AND oil" besides "bioremediation AND oil AND world oil reserve by regions."

\section{Results and Discussion}

Advancement in information communication technology makes it possible to generate and store huge amounts of searchable databases ${ }^{4}$. In general there are two types of databases, for profit and non-profit. Among the non-profit databases, the National Center for Biotechnology Information (NCBI)'s database role remains unprecedented in advancing science and health through open access to biomedical and genetic information all across the world. Our study utilizes PubMed database of the NCBI to retrieve information about bioremediation, a process in which living organisms, mainly bacteria, and fungi transform hazardous waste material into harmless products. We mainly focus on the use of bioremediation strategies to control oil spills that contribute towards environmental deterioration in ocean waters and sometime in small water reservoirs surrounding oil drilling operations in countries with rich oil production. Our access to PubMed database on October 30, 2015 by using simple subject search retrieved 36,017 records for bioremediation. In the PubMed database search there is the option for combining search terms with Boolean operators i.e. AND, OR, and NOT. It is essential that while implementing these Boolean operators uppercase characters should be used for these operators. The operator " $A N D$ " retrieve results that include all the search terms; "OR" retrieves results that include at least one of the search terms and "NOT" excludes the retrieval of terms from PubMed searches.

We used Boolean operator $A N D$ for our search terms including regions having oil reserves with bioremediation to identify whether the technology is recognized in the particular region or not. However, to identify what percentage of bioremediation research is linked to the oil industry, we used Boolean operator $A N D$ in the search "bioremediation AND oil." This search returned 2,408 records suggesting $7 \%$ of bioremediation research addresses oil industry issues. In next step, we include oil producing region in Boolean searches and these searches revealed that Asia and Oceania regions, having $3 \%$ of the crude oil reserves, show 1,400 publications manifesting this region's interests in bioremediation technology. Europe, having $1 \%$ of the oil reserves, is second on the list as far as bioremediation technology interest as is manifested by the number of publications in the PubMed database. The Middle East possesses $49 \%$ of the crude oil reserves, but we retrieved only 31 publications from PubMed database by using search term "bioremediation AND Middle East."

An interesting pattern was observed in our third set of searches by combining the region name $A N D$ bioremediation with the word oil. Intriguingly, the Middle East region stands out with $12 \%$ of their publication in the area of bioremediation are 
associated with oil when compared with other regions that have $10 \%$ of the bioremediation research in the area of oil.

Table 1

\begin{tabular}{|c|c|c|c|}
\hline Region & $\begin{array}{c}\text { Relative } \\
\text { Proportion of } \\
\text { Crude Oil } \\
\text { Reserves in } \\
\text { Percentage* }\end{array}$ & $\begin{array}{c}\text { PubMed } \\
\text { Articles } \\
\text { Numbers** } \\
\text { Search term = } \\
\text { Region Name } \\
\text { AND } \\
\text { Bioremediation }\end{array}$ & $\begin{array}{c}\text { PubMed } \\
\text { Articles } \\
\text { Numbers } * * * \\
\text { Search term= } \\
\text { Region name } \\
\text { AND } \\
\text { bioremediation } \\
\text { AND Oil }\end{array}$ \\
\hline $\begin{array}{l}\text { Middle } \\
\text { East }\end{array}$ & 49 & 31 & 4 \\
\hline $\begin{array}{l}\text { Central } \\
\text { and South } \\
\text { America }\end{array}$ & 20 & $\begin{array}{c}\text { Central } \\
\text { America }=2 \\
\text { South America } \\
\quad=12\end{array}$ & $\begin{array}{c}\text { Central America } \\
=0 \\
\text { South America }= \\
0\end{array}$ \\
\hline $\begin{array}{c}\text { North } \\
\text { America }\end{array}$ & 13 & 35 & 1 \\
\hline Africa & 8 & 291 & 31 \\
\hline Eurasia & 7 & 0 & 0 \\
\hline $\begin{array}{l}\text { Asia and } \\
\text { Oceania }\end{array}$ & 3 & $\begin{array}{l}\text { Asia }=1305 \\
\text { Oceania }=71\end{array}$ & $\begin{array}{c}\text { Asia }=136 \\
\text { Oceania }=3\end{array}$ \\
\hline Europe & 1 & 1206 & 123 \\
\hline
\end{tabular}

*Data Source: US Energy Information Administration (2013)

** PubMed Database search with the term region name AND bioremediation through simple subject search (Access Date: October $30,2015)$

***Boolean operator AND used for defining logical relationship in the search term including region name AND oil AND bioremediation (Access Date: October 30, 2015)

Historically, ocean and waterway contamination with oil has been a major issue, because of oil transportation through sea routes. Better ship designs and strict oil transportation regulations have significantly reduced oil spillage into oceans; however, according to The National Academics of Sciences, Engineering and Medicine report in the decade of $1990-1999$, an average of 150,000 tons of oil spilled into waterways annually ${ }^{5}$. However, among all these Exxon Valdez oil spill in Prince William Sound in Alaska was a wakeup call for the world to have precautionary measures in place in the event of any future oil spills.

To minimize the hazardous impact of oil spills mechanical containments employ barriers, booms, skimmers, and synthetic sorbents; chemical and biological containment is through oil dispersing or gelling agents and biological agents (bioremediation). Lessons learned from all these methodologies suggest that judicious use of biological agents is more effective in situations when immediate mechanical containments methods have not been implemented. Developed nations have defined protocols for oil spill control technologies; however, every nation having crude oil reserves should have such measures in place.

The drilling processes in the oil rich areas also affect lives of the people in peripheries. Contamination of drinking water, top soil, and livestock in peripheries are prone to hazards of oil contamination. In the recent past, an online database has been developed in the form of a repository of information relevant to effects of oil on human health ${ }^{7}$.

Our analyses also reveals that the share of the Middle East relevant to utilization of bioremediation, the most cost effective methodology of oil spill control, is relatively less. There is a strong need for establishing interdisciplinary programs aimed at keeping the environment clean with particular reference to the oil industry in this region. This situation demands the strengthening of biotechnology programs and the enhancing of interdisciplinary interactions between biotechnology and engineering.

\section{References}

[1] US Bioremediation Markets http://www.frost.com/prod/servlet/reportbrochure.pag?id=7857-01-00-00-00

[2] Bioremediation Technologies and Services Market Global Industry Analysis, Size, Share, Growth, Trends and Forecast, $2013 \quad-\quad 2019 \quad$ (2013) http://www.transparencymarketresearch.com/bioremediati on-technologies-services.html

[3] PubMed

http://www.ncbi.nlm.nih.gov/pubmed/?term=

[4] Zou D, Ma L, Yu J, Zhang Z. (2015) Biological databases for human research. Genomics Proteomics Bioinformatics.13(1):55-63.

[5] Oil in the sea III." National Academies" (2002) http://dels.nas.edu/dels/rpt_briefs/oil_in_the_sea_final.pdf

[6] Nomack M (2010) Oil spill control technologies. http://www.eoearth.org/view/article/158385

[7] Oil contamination health effects https://sites.google.com/site/oilcontaminationhealtheffects /home 